\title{
Input-Specific GABAergic Signaling to Newborn Neurons in Adult Dentate Gyrus
}

\author{
Sean J. Markwardt, Jacques I. Wadiche, and Linda S. Overstreet-Wadiche \\ Department of Neurobiology and Evelyn McKnight Brain Institute, University of Alabama at Birmingham, Birmingham, Alabama 35294
}

\begin{abstract}
Adult neurogenesis is the multistage process of generating neurons from adult neural stem cells. Accumulating evidence indicates that GABAergic depolarization is an important regulator of this process. Here, we examined GABAergic signaling to newly generated granule cells (GCs) of the adult mouse dentate gyrus. We show that the first synaptic currents in newborn GCs are generated by activation of $\mathrm{GABA}_{\mathrm{A}}$ receptors by GABA with a spatiotemporal profile suggestive of transmitter spillover. However, the GABAergic response is not attributable to spillover from surrounding perisomatic synapses. Rather, our results suggest that slow synaptic responses in newborn GCs are generated by dedicated inputs that produce a relatively low concentration of GABA at postsynaptic receptors, similar to slow IPSCs in mature GCs. This form of synaptic signaling drives robust phasic depolarization of newborn GCs when the interneuron network is synchronously active, revealing a potential mechanism that translates hippocampal activity into regulation of adult neurogenesis via synaptic release of GABA.
\end{abstract}

\section{Introduction}

Neurogenesis persists in the dentate gyrus and olfactory system of adult mammals. In the dentate gyrus, neural progenitors proliferate and differentiate into newborn neurons that undergo a protracted maturational period culminating in full integration in the hippocampal network (Ge et al., 2008). A striking feature of adult neurogenesis is its sensitivity to many conditions, including exercise, environmental enrichment, and seizures. This regulation supports the idea that activity-dependent control of adult neurogenesis enables adaptive network plasticity in response to physiological and pathological demands. Accordingly, multiple stages of neurogenesis, including progenitor proliferation, neural differentiation, and neural maturation are regulated by neural activity (Markwardt and Overstreet-Wadiche, 2008). One attractive mechanism for activity-dependent regulation of adult neurogenesis involves direct depolarization of neural progenitors that promotes neural differentiation, termed "excitation-neurogenesis coupling" (Deisseroth et al., 2004). In vivo, excitation-neurogenesis coupling is likely achieved by depolarizing GABAergic input (Tozuka et al., 2005), because hippocampal progenitors and newborn neurons first receive depolarizing GABAergic input before glutamatergic synapses are established (Espósito et al., 2005; Overstreet-Wadiche et al., 2005; Tozuka et al., 2005). In addition, during the first weeks after cell birth, GABAergic depolarization promotes morphological and functional maturation, allowing newborn neurons to become inte-

\footnotetext{
Received May 28, 2009; revised July 23, 2009; accepted 0ct. 13, 2009.

This work was supported by the Epilepsy Foundation, National Institutes of Health (NIH) Neuroscience Blueprint Core Grant NS57098 (University of Alabama at Birmingham), and NIH Grant NS064025. We thank members of the Wadiche Laboratories for helpful suggestions.

Correspondence should be addressed to Linda S. Overstreet-Wadiche, Department of Neurobiology, Shel 1003, University of Alabama at Birmingham, Birmingham, AL 35294. E-mail: Iwadiche@uab.edu. D0I:10.1523/JNEUROSCI.2727-09.2009

Copyright $\odot 2009$ Society for Neuroscience $\quad$ 0270-6474/09/2915063-10\$15.00/0
}

grated into the hippocampal network (Ge et al., 2006). GABAergic signaling is thus poised to control multiple stages of activity-dependent regulation of adult neurogenesis.

There are several forms of GABAergic signaling in the brain (Farrant and Nusser, 2005). Synaptic or "phasic" inhibition refers to postsynaptic responses activated by GABA released from presynaptic vesicles, whereas tonic inhibition refers to activation of $\mathrm{GABA}_{\mathrm{A}}$ receptors by low ambient levels of GABA that accumulate in the extracellular space. Phasic responses are mediated by inputs targeted to specific domains of principal cells in a manner related to distinctive functional roles, with perisomatic synapses controlling the timing of neuronal output (Cobb et al., 1995; Pouille and Scanziani, 2001), and dendritic synapses controlling the integration of excitatory inputs (Miles et al., 1996). Typically, dendritic stimulation evokes slow IPSCs (also called GABA $_{\mathrm{A}, \text { slow }}$ ) and stimulation near the soma evokes fast IPSCs $\left(\mathrm{GABA}_{\mathrm{A}, \text { fast }}\right)$ (Pearce, 1993; Soltesz et al., 1995; Laplagne et al., 2006, 2007). Both the subunit composition of the receptors and the spatiotemporal characteristics of the GABA concentration transient contribute to the time course of GABA-mediated responses (Mozrzymas, 2004; Farrant and Nusser, 2005). Whereas low steady-state levels of GABA mediate tonic inhibition, a brief and high GABA transient generates fast IPSCs. Slow IPSCs, however, have been attributed to specific synapses with characteristics intermediate between phasic and tonic inhibition (Szabadics et al., 2007) or to nonspecific spillover of GABA between neighboring synapses that mediate fast IPSCs (Rossi and Hamann, 1998). In the dentate gyrus, adult generated granule cells (GCs) first receive tonic and slow phasic GABAergic input (Espósito et al., 2005; OverstreetWadiche et al., 2005; Ge et al., 2006; Karten et al., 2006), but it is not clear how these forms of signaling contribute to activitydependent depolarization.

Here, we explore the mechanisms underlying slow postsynaptic currents (PSCs) in newborn GCs. We first compare the spa- 
tiotemporal characteristics of GABA at slow synapses on newborn GCs with fast synapses on mature GCs evoked by the same stimulus. Newborn GCs are located in a region with a high density of fast perisomatic inputs, so we also test whether nonspecific GABA spillover from mature neighboring synapses underlies slow PSCs. We conclude that, although slow PSCs display some features of spillover, they are most consistent with responses arising from dedicated inputs similar to $\mathrm{GABA}_{\mathrm{A} \text {,slow }}$ produced at unitary synapses in the cortex (Szabadics et al., 2007). Our results further suggest that depolarization mediated by slow GABAergic signaling may provide input-specific modulation of GC maturation in response to hippocampal network activity.

\section{Materials and Methods}

We used 6- to 10-week-old hemizygous transgenic mice with green fluorescent protein expressed under control of the proopiomelanocortin promoter (POMC-EGFP) (Cowley et al., 2001; Overstreet et al., 2004) maintained in a C57BL/6J background. All animal procedures followed the Guide for the Care and Use of Laboratory Animals, U.S. Public Health Service, and were approved by the University of Alabama at Birmingham Institutional Animal Care and Use Committee. Mice were anesthetized and perfused intracardially with ice-cold modified artificial CSF containing the following (in $\mathrm{mM}$ ): 110 choline chloride, $26 \mathrm{D}$-glucose, $2.5 \mathrm{MgCl}_{2}$, $2.5 \mathrm{KCl}, 1.25 \mathrm{Na}_{2} \mathrm{PO}_{4}, 0.5 \mathrm{CaCl}_{2}, 1.3 \mathrm{Na}$-ascorbate, $3 \mathrm{Na}$-pyruvate, and $25 \mathrm{NaHCO}_{3}$, bubbled with $95 \% \mathrm{O}_{2} / 5 \% \mathrm{CO}_{2}$. The brain was removed and $350-\mu \mathrm{m}$-thick hippocampal slices were prepared using a vibratome (Vibratome $3000 \mathrm{EP}$ ). Slices were incubated at $37^{\circ} \mathrm{C}$ for $\sim 30$ min in recording solution containing the following (in $\mathrm{mM}$ ): 125 $\mathrm{NaCl}, 2.5 \mathrm{KCl}, 1.25 \mathrm{Na}_{2} \mathrm{PO}_{4}, 2 \mathrm{CaCl}_{2}, 1 \mathrm{MgCl}_{2}, 25 \mathrm{NaHCO}_{3}$, and 25 D-glucose bubbled with $95 \% \mathrm{O}_{2} / 5 \% \mathrm{CO}_{2}$, and then transferred to room temperature in the same solution.

Patch pipettes were filled with the following (in mM): $120 \mathrm{~K}$-gluconate, $15 \mathrm{KCl}, 4 \mathrm{MgCl}_{2}$, $10 \mathrm{HEPES}, 4 \mathrm{Mg}$-ATP, $0.3 \mathrm{Na}-\mathrm{GTP}, 7$ phosphocreatine, and 0.1 EGTA, pH 7.3 and $310 \mathrm{mOsm}(4-6 \mathrm{M} \Omega)$. In some experiments, biocytin $(0.2 \%)$ was included for morphological visualization after recording using Cy3-conjugated streptavidin. A patch pipette filled with extracellular solution was used to evoke synaptic currents $(20 \mu \mathrm{s}$; 15-95 V). Monosynaptic evoked GABAergic currents were isolated with NBQX (1,2,3,4-tetrahydro-6-nitro-2,3-dioxo-benzo[f]quinoxaline-7sulfonamide) $(10 \mu \mathrm{M})$ and AP5 $(50 \mu \mathrm{M})$ or kynurenic acid (3-5 mM). All recordings were done at $22^{\circ} \mathrm{C}$ and at a holding potential of $-70 \mathrm{mV}$. Series resistance was uncompensated (10-25 M $\Omega$ ), and experiments were discarded if substantial changes $(>15 \%)$ were observed. Voltages were not corrected for junction potentials. Currents were filtered at $2 \mathrm{kHz}$ and sampled at $10 \mathrm{kHz}$ (MultiClamp 700B; Molecular Devices). In experiments in which the extracellular $\left[\mathrm{Ca}^{2+}\right]$ was altered, the concentration of divalent ions was maintained with $\mathrm{Mg}^{2+}$. The decay of synaptic currents was fit with one or two exponentials and described by the weighted decay $\tau$ calculated from the equation $A_{x} \tau_{1}+A_{x} \tau_{2}$, where $A$ is the relative amplitude of each component and $\tau$ is its time constant. Spontaneous synaptic activity was recorded in $5 \mathrm{~min}$ epochs and analyzed off-line using the template-matching protocol in Axograph X (Axograph Scientific) as in the study by Overstreet and Westbrook (2001). Correlated spontaneous events in newborn and mature GCs were first analyzed as in the study by Matsui and Jahr (2003), averaging 60-3300 detected events per pair. The timing of coincident events was examined by manually selecting all events that occurred within a $5 \mathrm{~ms}$ window in each pair. The onset of each event was measured by setting $t=0$ at several milliseconds before the onset of one event, and then calculating the time at which each event reached $10 \%$ of the maximal peak amplitude (see also supplemental Fig. 3, available at www.jneurosci.org as supplemental material).

Confocal images were taken of POMC-EGFP expression in a perfusion-fixed adult mouse ( $50 \mu \mathrm{m}$ sections) and from a biocytin-filled mature GC in an acute slice $(350 \mu \mathrm{m})$ after overnight fixation as described by Overstreet-Wadiche et al. (2006).

Data are expressed as mean \pm SEM. When data sets were normally distributed, we used two-tailed paired or unpaired $t$ tests to determine statistical significance at $p<0.05$. When data sets did not pass a normal- ity test, Wilcoxon matched pairs or Mann-Whitney tests were used to determine statistical significance. Drugs and chemicals were obtained from Sigma-Aldrich, Tocris Bioscience, or Ascent Scientific.

\section{Results}

Initial synaptic currents in adult generated neurons are slow We used expression of EGFP in the dentate gyrus of POMCEGFP transgenic mice to identify adult generated GCs. In these reporter mice, EGFP is transiently expressed at an early stage of maturation distinguished by short dendrites that do not extend through the entire molecular layer (Fig. 1a) (Overstreet et al., 2004). The mature morphology of unlabeled GCs was visualized by including biocytin in the recording pipette (Fig. $1 b$ ). POMCEGFP expression occurs during the first weeks after cell division, when newborn GCs have exclusively $\mathrm{GABA}_{\mathrm{A}}$ receptor-mediated synaptic input that has distinctive slow rise and decay phases (Espósito et al., 2005; Overstreet-Wadiche et al., 2005). We used focal stimulation at the border between the granule cell layer and inner molecular layer (in the termination zone of newborn GC dendrites) (Fig. 1c), to evoke monosynaptic GABAergic input to newborn and neighboring mature GCs. Stimulation in this location, presumably activating a similar population of afferent fibers, evoked synaptic responses with different kinetics. PSCs in newborn GCs had prolonged rise and decay phases compared with IPSCs in neighboring mature granule cells $(20-80 \%$ rise, $5.7 \pm 0.3 \mathrm{~ms}$ in newborn GCs, $n=18$, vs $1.1 \pm 0.1 \mathrm{~ms}$ in mature GCs, $n=18, p<0.001$; weight decay $\tau=86.4 \pm 4.7 \mathrm{~ms}$ in newborn GCs vs $40.0 \pm 4.5 \mathrm{~ms}$ in mature GCs, $p<0.001$ ) (Fig. $1 d)$. Stimulation of the middle molecular layer evoked IPSCs in mature GCs with similar slow kinetics as slow PSCs newborn GCs $(5.6 \pm 0.5 \mathrm{~ms}$ rise; $\tau$ decay $=89 \pm 19 ; n=4)$ (data not shown) (Laplagne et al., 2006; 2007). At $34^{\circ} \mathrm{C}$, the rise time of PSCs evoked by GCL stimulation in newborn GCs remained slower than IPSCs in mature GCs $(3.1 \pm 0.4$ and $0.62 \pm 0.2 \mathrm{~ms}$, respectively; $n=3$ each; $p<0.003$ ) (data not shown) and the difference in the decay $\tau$ was likewise maintained $(30.6 \pm 3.9 \mathrm{~ms}$ in newborn GCs; $8.2 \pm 0.3 \mathrm{~ms}$ in mature GCs; $n=3$ each; $p<0.005)$. Thus, in mature GCs, slow IPSCs arise from synapses preferentially recruited by dendritic stimulation and fast IPSCs arise from perisomatic-projecting inputs recruited by somatic stimulation (Soltesz et al., 1995). In contrast, both somatic and dendritic stimulation generate exclusively slow synaptic responses in newborn GCs (Espósito et al., 2005; Overstreet-Wadiche et al., 2005).

The slow decay of the PSC in newborn GCs could be a result of dendritic filtering. To directly test this possibility, we applied a voltage jump during the PSC. If the voltage jump is capable of changing the current, this implies that the synaptic conductance is still active at the time of the jump (Pearce, 1993; Häusser and Roth, 1997). We found that a voltage step applied $50 \mathrm{~ms}$ after the synaptic stimulation increased the current amplitude by $28 \pm 4 \%$ $(n=4 ; p<0.01)$ (supplemental Fig. 1, left, gray trace, available at www.jneurosci.org as supplemental material). Even at $80 \mathrm{~ms}$ after the synaptic stimulation, the voltage jump increased the synaptic current (by $11 \% ; n=2$ cells) (supplemental Fig. 1, right, gray trace, available at www.jneurosci.org as supplemental material), indicating the synaptic conductance was still active. These data suggest that the slow decay of the PSC is not generated by electrotonic filtering of fast distal responses, but rather a slow membrane conductance.

\section{Manipulating the synaptic GABA transient}

At typical fast CNS synapses, the synaptic neurotransmitter concentration is brief ( $<1 \mathrm{~ms}$ ) (Clements, 1996), such that receptor 

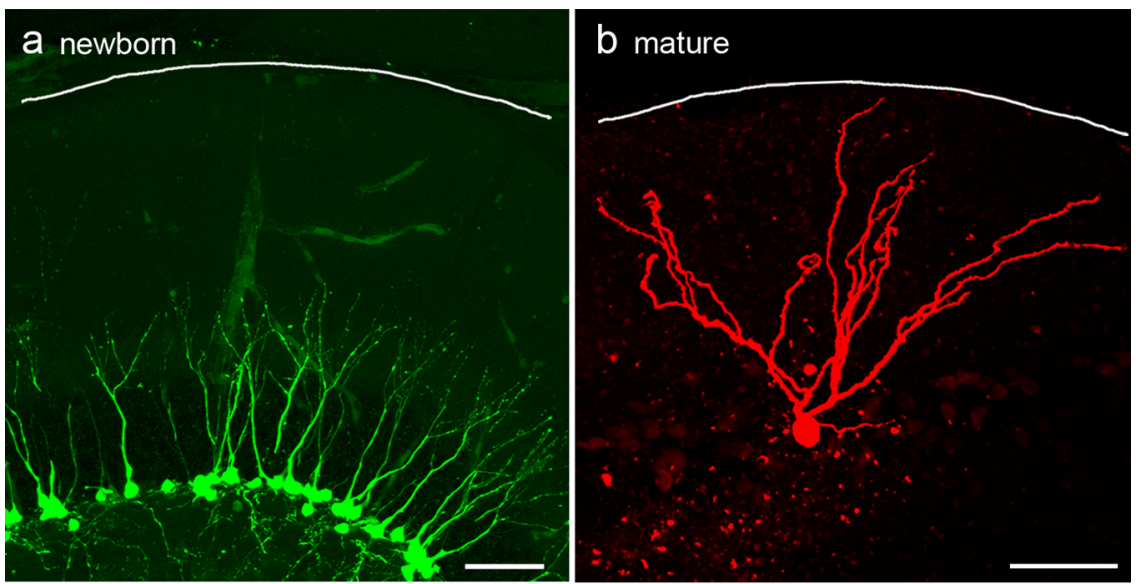

C

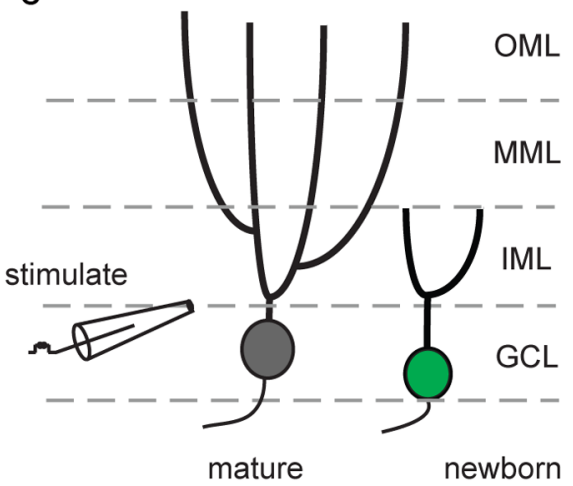

d newborn

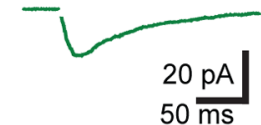

mature

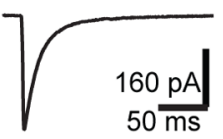

normalized

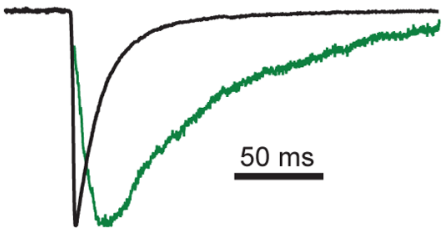

Figure 1. Initial synaptic currents in adult generated neurons are slow. $\boldsymbol{a}$, POMC-EGFP-labeled GCs illustrate the immature morphology of newborn GCS. The white line approximates the outer edge of the molecular layer. $\boldsymbol{b}$, The mature morphology of unlabeled neighboring $\mathrm{GCs}$ is illustrated by biocytin fills during recording in acute slices. Scale bars: $\boldsymbol{a}, \boldsymbol{b}, 50 \mu \mathrm{m}$. $\boldsymbol{c}$, Representation of cell morphologies and location of focal stimulating electrode. Green, Newborn GC; gray, mature GC. GCL, Granule cell layer; IML, inner molecular layer; MML, middle molecular layer; OML, outer molecular layer. $\boldsymbol{d}$, Synaptic stimulation evoked PSCs in newborn cells with slow rise and decay kinetics, whereas stimulation at the same location evoked IPSCs in neighboring mature granule cells that are larger and faster. In all figures, stimulus artifacts are blanked for clarity. Glutamate receptor antagonists were used to isolate monosynaptic GABAergic input (see Materials and Methods).
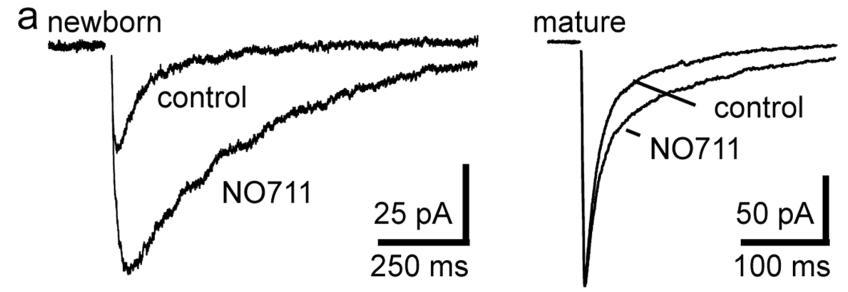

b
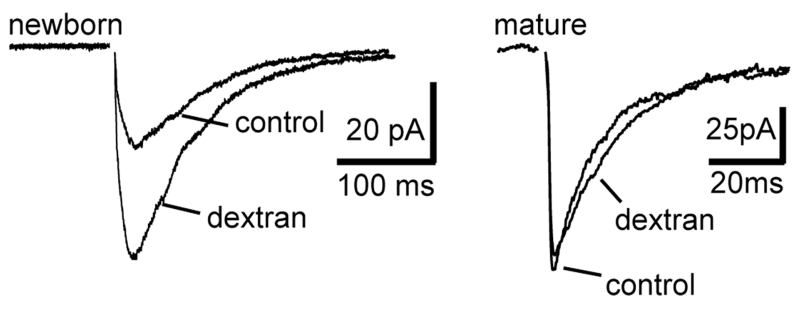

Figure 2. Manipulating the GABA transient reveals different synaptic GABA profiles in newborn GCs and mature GCs. $\boldsymbol{a}$, The GABA transporter inhibitor N0711 enhanced the amplitude and prolonged the decay of slow PSCs in newborn GCS (left), whereas in mature GCs (right), N0711 only modestly prolonged the decay of fast IPSCS. The prolongation of the weighted decay in mature GCs was mediated entirely by an increase in the amplitude of the slow component (slow component from $106 \pm 5$ to $178 \pm 21$ ms in N0711; $p<0.05$ ). $\boldsymbol{b}$, Dextran increased the amplitude of PSCs in newborn cells (left) but did not affect the amplitude of $\mathrm{GABA}_{\mathrm{A}}$-IPSCs in mature cells (right). kinetics primarily determines the time course of the synaptic response. However, diffusion of GABA outside the synapse (i.e., spillover) can result in slow synaptic responses at neighboring sites that are more sensitive to the timing of the GABA transient (Isaacson et al., 1993; Rossi and Hamann, 1998). Because GABA transporters (GATs) limit spillover, we first compared the effect of the GAT1 inhibitor 1-[2([(diphenylmethylene)imino] oxy) ethyl]-1,2,5,6-tetrahydro-3-pyridinecarboxylic acid hydrochloride (NO711) on slow PSCs in newborn GCs. NO711 (10 $\mu \mathrm{M})$ enhanced the amplitude of GABAergic PSCs in newborn GCs by $86 \pm 12 \%$ (from $30 \pm 2$ to $55 \pm 5 \mathrm{pA}$ in NO711; $n=$ $8 ; p<0.001$ ) (Fig. $2 a$, left). NO711 also slowed the time course of PSCs by slowing the $20-80 \%$ rise time (to $298 \pm 30 \%$ of control; $p<0.01$ ) and the decay $\tau$ (to $356 \pm 40 \%$ of control; $p<0.01$ ). Conversely, NO711 caused a slight reduction in the amplitude of fast IPSCs in mature GCs (from $206 \pm 10$ to $182 \pm 2 \mathrm{pA} ; n=4$; $p=0.04)$, with no change in the rise time (112 $\pm 22 \%$ of control; $p>0.7$ ). Notably, NO711 caused a twofold greater prolongation in the weighted decay $\tau$ of slow PSCs compared with fast IPSCs (to $178 \pm$ $18 \%$ of control; $p<0.01$ ) (Fig. $2 a$, right). The dramatic effect of NO711 on PSCs in newborn GCs is consistent with a spillover mode of transmission and suggests that the synaptic GABA transient underlying fast and slow responses is fundamentally different.

In newborn GCs, the baseline current noise was also increased by NO711 (to $195 \pm 20 \%$ of control) and subsequently decreased by picrotoxin (by $74 \pm 3 \% ; n=5 ; p<0.01$, ANOVA) (supplemental Fig. 2, available at www.jneurosci.org as supplemental material), consistent with the presence of tonic $\mathrm{GABA}_{\mathrm{A}}$ receptor-mediated activity (Ge et al., 2006). Under our conditions using near physiological intracellular $\left[\mathrm{Cl}^{-}\right]$and $\left[\mathrm{K}^{+}\right]$, the changes in current noise produced by NO711 and picrotoxin were not associated with significant shifts in the holding current $(-3.5 \pm 2.5 \mathrm{pA}$; $p=0.24)$, possibly because of the small driving force for $\mathrm{Cl}^{-}$. We therefore focused exclusively on synaptic (phasic) GABAergic signaling.

We next sought to manipulate the synaptic GABA transient by altering GABA mobility. Increasing the viscosity of the extracellular space with the inert molecule dextran impedes the diffusion of small molecules and thus enhances the synaptic concentration of neurotransmitter, leading to enhanced activation (occupancy) of both presynaptic and postsynaptic receptors (Min et al., 1998). In the presence of (2S)-3-\{[(1S)-1-(3,4-dichlorophenyl) ethyl]amino-2-hydroxypropyl $\}$ (phenylmethyl)phosphinic acid (CGP55845) $(2 \mu \mathrm{M})$ to prevent changes in GABA release by activation of presynaptic $\mathrm{GABA}_{\mathrm{B}}$ receptors, we found that dextran $(40 \mathrm{kDa} ; 5 \%)$ increased the amplitude of PSCs in newborn GCs by $113 \pm 28 \%$ (from $27 \pm 2$ to $57 \pm 7 \mathrm{pA} ; n=7 ; p<0.01$ ) while having no effect on the amplitude of fast IPSCs in mature GCs 
(from $89 \pm 9$ to $111 \pm 33 \mathrm{pA} ; n=7 ; p=0.4$ ) (Fig. $2 b$ ). These results suggest that GABA does not saturate receptors underlying slow PSCs in newborn GCs and that impaired diffusion enhances the [GABA] transient resulting in greater postsynaptic receptor occupancy (Perrais and Ropert, 2000). The increase in amplitude was not associated with a change in the rise time (101 $\pm 8 \%$ of control), suggesting a low GABA concentration is not the ratelimiting step slow rise time of the PSC. The lack of effect in mature GCs suggests that in the impaired diffusion does not significantly affect the peak concentration of GABA or the postsynaptic receptors are close to saturation. In principal, dextran could also have discrepant effects on the decay time course of synaptic responses. If impaired diffusion restricts the escape of neurotransmitter from the synaptic cleft, synaptic responses could be prolonged. Alternatively, if impaired diffusion limits the activation of distant extrasynaptic receptors, synaptic responses mediated by spillover could be accelerated. Dextran did not affect the decay $\tau$ of fast IPSCs (to $123 \pm 13 \%$ of control; $n=7 ; p=0.2$ ) but accelerated the decay $\tau$ of slow PSCs (to $91 \pm 3 \%$ of control; $n=$ $7 ; p=0.02$ ). These results suggest that impaired GABA diffusion differentially affected both the amplitude and time course of synaptic currents in newborn and mature GCs. The increased amplitude of PSCs in newborn GCs indicates that the underlying receptors are far from saturation, possibly because of a low concentration of GABA.

\section{The synaptic [GABA]}

To directly test the relative concentration of GABA at newborn and mature synapses, we performed a low-affinity antagonist experiment. The sensitivity of synaptic currents to inhibition by a low-affinity competitive antagonist provides a measure of the concentration of transmitter experienced by postsynaptic receptors, as high concentrations of transmitter more effectively displace antagonist that unbinds during the transmitter transient (Clements, 1996). We found that slow PSCs in newborn GC were blocked to a greater extent by the low-affinity antagonist $(1,2,5,6$ tetrahydropyridin-4-yl)methylphosphinic acid (TPMPA) (200 $\mu \mathrm{M}$ ) than fast IPSCs in mature granule cells (Fig. 3). Whereas slow PSCs were reduced to $53 \pm 5 \%$ of control (from $30 \pm 3$ to $16 \pm 3 \mathrm{pA} ; n=6)$, fast IPSCs were reduced to only $69 \pm 3 \%$ of control (from $76 \pm 5$ to $53 \pm 5 \mathrm{pA} ; n=5$ ). Importantly, the high-affinity antagonist gabazine $(80 \mathrm{nM})$ was equally efficacious at both types of synapses (to $51 \pm 4 \%$ in newborn cells, $n=6$; compared with $53 \pm 6 \%$ in mature cells, $n=5 ; p=0.3$ ), indicating rapid unbinding of TPMPA was necessary for the differential block. The differential block by the low-affinity, but not highaffinity, antagonist is consistent with the idea that slow PSCs in newborn granule cells are generated by a lower concentration of GABA. We also found that slow IPSCs in mature granule cells evoked by stimulation of the middle molecular layer were blocked by TPMPA to a greater extent than fast perisomatic evoked IPSCs (to $50 \pm 1 \% ; n=5 ; p<0.001$ ) (data not shown), whereas the sensitivity to gabazine was similar $(53 \pm 5 \% ; n=5)$. Thus, slow PSCs in both mature GCs and newborn GCs appear to be generated by a relatively low concentration of GABA compared with fast IPSCs. In addition to providing a measure of the peak neurotransmitter concentration, low-affinity antagonists can also report on slower phases of the transmitter transient. For example, speeding of the current decay by a low-affinity antagonist suggests that the slow component of the response is generated by a lower concentration of transmitter as could occur by spillover (Diamond, 2001; Overstreet and Westbrook, 2003), whereas prolongation of the decay suggests the peak transmitter a

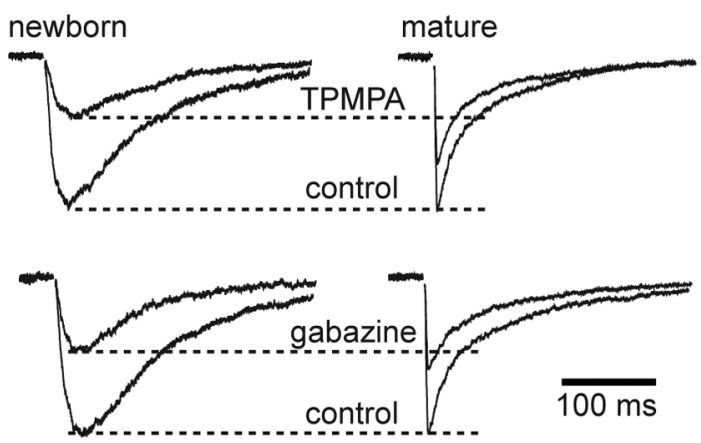

b

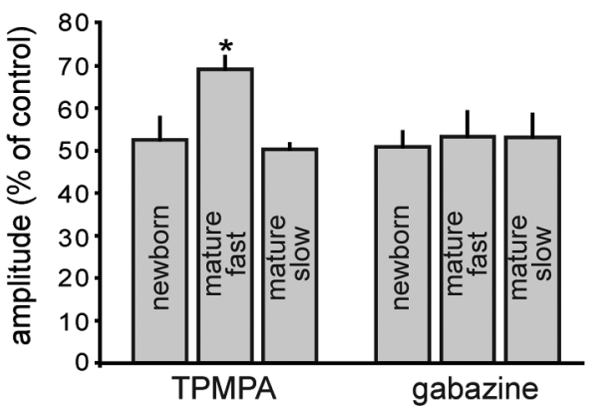

Figure 3. Synaptic GABA concentrations differ between fast and slow responses. $\boldsymbol{a}$, The low-affinity GABA antagonist TPMPA (200 $\mu \mathrm{M})$ produced a greater block in newborn GCs than in mature GCS (top). However, subsequent addition of the high-affinity antagonist gabazine $(100 \mathrm{~nm})$ blocked synaptic currents to a similar extent (bottom). Traces were normalized to the peak amplitude in each control condition. $\boldsymbol{b}$, Histograms illustrating the enhanced sensitivity of slow PSCs to TPMPA. GABA $A_{\text {, slow }}$ IPSCs in mature GCs evoked by stimulation of the MML (mature slow) also showed enhanced sensitivity to TPMPA. Error bars indicate SEM. ${ }^{*} p<0.05$.

concentration persists for long enough to allow displacement of the antagonist (Overstreet et al., 2002). TPMPA tended to slow the decay of slow responses in newborn (to $115 \pm 8 \%$ of control; $n=6 ; p=0.1$ ) and mature GCs (to $119 \pm 8 \%$ of control; $n=4$; $p=0.08)$. Conversely, TPMPA speeded the weighted decay of fast IPSCs in mature GCs (to $80 \pm 7 \%$ of control; $n=5$; $p<$ 0.05 ), as was reported with a different low-affinity antagonist (Overstreet and Westbrook, 2003). The differential effects of TPMPA on both the amplitude and decay of fast and slow synaptic currents suggests that the GABA concentration transient underlying slow synaptic responses is lower and longer than at perisomatic synapses underlying fast IPSCs.

\section{Spillover versus specific inputs}

The results presented thus far suggest that the GABA transient underlying PSCs in newborn GCs has characteristics consistent with GABA spillover. GCs at this early developmental stage could lack direct synaptic input but instead respond to GABA released from neighboring fast perisomatic synapses on mature GCs. Alternatively, newborn GCs could receive synaptic input from interneurons that generate $\mathrm{GABA}_{\mathrm{A} \text {,slow }}$ in mature GCs (Espósito et al., 2005), using a mode of transmission that has some characteristics of spillover despite the presence of anatomically identified synaptic junctions (Tamás et al., 2003; Szabadics et al., 2007). The following experiments were designed to distinguish between these possibilities.

To test the idea that slow PSCs in newborn GCs are generated by spillover from synchronous release of GABA from neighboring fast perisomatic synapses onto mature GCs, we sought to decrease spillover by reducing the density of active release sites via 
a
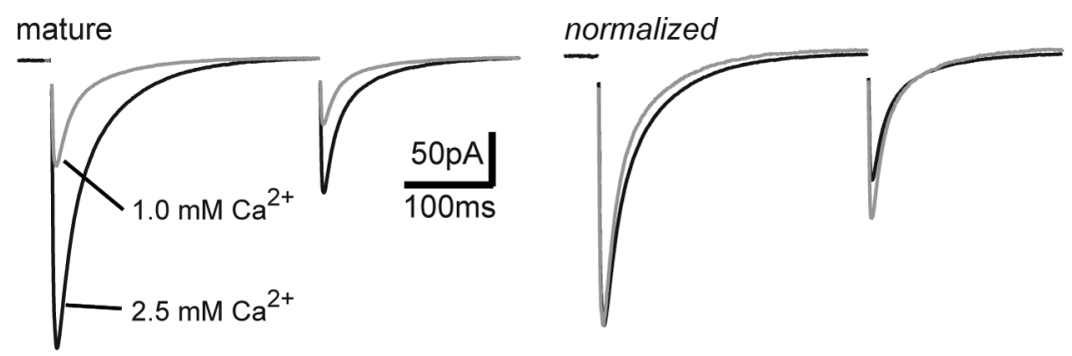

b

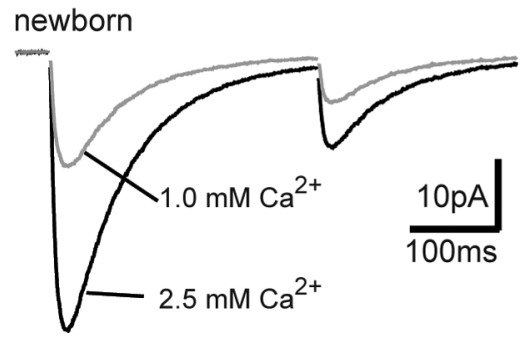

normalized

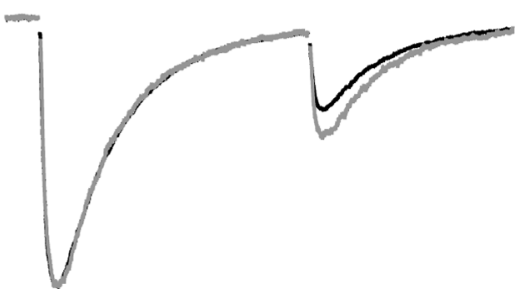

Figure 4. Reducing spillover does not affect the kinetics of PSCs in newborn GCs. $\boldsymbol{a}$, Reducing extracellular $\left[\mathrm{Ca}^{2+}\right]$ decreased the amplitude of IPSCs in mature GCs by $\sim 60 \%$ (left) and increased the paired-pulse ratio (right), as expected for a reduction in Pr. Reduced GABA release was accompanied by a speeding of the IPSC decay (right). $\boldsymbol{b}$, In newborn GCS, reduced extracellular [Ca ${ }^{2+}$ ] decreased the amplitude to the same extent (left) and increased the paired-pulse ratio of slow PSCs (right). However, the decay of slow PSCs was not altered.

reducing release probability $(\mathrm{Pr})$. Because spillover requires a cooperative, nonlinear pooling of transmitter from multiple sites (Scanziani, 2000), spillover-mediated responses will be more sensitive to reduced Pr compared with the originating direct synaptic responses. In mature GCs, reducing the extracellular $\left[\mathrm{Ca}^{2+}\right]$ from 2.5 to $1 \mathrm{~mm}$ reduced the amplitude and increased the paired-pulse ratio (PPR) of fast IPSCs from $0.46 \pm 0.04$ to $0.6 \pm$ $0.04(n=4 ; p<0.001)$ (Fig. $4 a)$, indicating a decrease in $\operatorname{Pr}$ and thus a reduction in the number of neighboring synapses releasing GABA. These changes were accompanied by a speeding of the decay (decay $\tau$ from $36 \pm 3$ to $30 \pm 4 \mathrm{~ms} ; n=4 ; p<0.05$ ), as expected to occur when spillover contributes to the slow component of a synaptic response (Overstreet and Westbrook, 2003; Biró and Nusser, 2005). In newborn GCs, reducing the extracellular $\left[\mathrm{Ca}^{2+}\right.$ ] from 2.5 to $1 \mathrm{~mm}$ also reduced the amplitude and increased the PPR of slow PSCs from $0.29 \pm 0.02$ to $0.40 \pm 0.03$ $(n=5 ; p<0.05)$, with no change in the decay $\tau$ (from $78 \pm 10$ to $77 \pm 7 \mathrm{~ms} ; n=5)$. Importantly, the amplitude reduction in newborn and mature GCs was similar (to $41 \pm 3$ and $37 \pm 7 \%$ of control, respectively; $p>0.5$ ), suggesting that slow PSCs are not generated by GABA spillover from synapses generating fast IPSCs. The lack of kinetic change of slow PSCs under low Pr conditions cannot be used to differentiate between nonspecific spillover and direct inputs, since it could reflect either an entirely spillovermediated response or input from specific interneuron subtypes that generate slow IPSCs (Szabadics et al., 2007).

Alternatively, if slow PSCs in newborn GCs are generated at synapses in a manner similar to $\mathrm{GABA}_{\mathrm{A} \text {,slow }}$ in mature GCs, we predicted that simultaneous slow spontaneous synaptic events in newborn and mature GCs would arise from a common presynaptic interneuron. Indeed, in five of five dual recordings from newborn and mature GC pairs $(<100 \mu \mathrm{m})$, we observed coincident spontaneous synaptic currents (sIPSCs/sPSCs) (Fig. 5a). To analyze coincident events, we first detected all slow and fast spontaneous events using templates with slow $\left(\tau_{\text {rise }}=5 \mathrm{~ms} ; \tau_{\text {decay }}=50\right.$ $\mathrm{ms})$ and fast kinetics $\left(\tau_{\text {rise }}=0.5 \mathrm{~ms} ; \tau_{\text {decay }}=10 \mathrm{~ms}\right)$, respectively.
Detected events were aligned by their onset, along with the corresponding traces in the simultaneously recorded cell (Fig. 5b). In newborn GCs, only slow events were detected. When sPSCs in a newborn GC were aligned and averaged, a slow sIPSC was apparent in the neighboring mature GC (Fig. $5 c$, left). The same procedure with detected fast sIPSCs in mature GCs resulted in no measurable averaged event in newborn GCs (Fig. 5c, middle). However, when slow sIPSCs detected in mature GCs were aligned, a slow PSC in the newborn GC was again revealed (Fig. $5 c$, right). sPSCs in newborn GCs had similar rise times as $\mathrm{GABA}_{\mathrm{A} \text {,slow }}$ in mature GCs, but slower decay time constants (Table 1). These results suggest that sPSCs in newborn GCs are coincident with slow, but not fast, sIPSCs in mature GCs. We then quantified all the correlated events, defined as events that occur in both cells within a $5 \mathrm{~ms}$ time window. On average, $1.5 \%$ of slow IPSCs in mature GCs were correlated with sPSCs in the neighboring newborn and $21.5 \%$ of sPSCs in newborn GCs were correlated with slow sIPSCs in the neighboring mature GC. These rates of coincidence, along with the relative rates of spontaneous activity (Table 1), suggest that mature GCs are innervated by a larger number of interneurons that generate slow IPSCs and that a fraction of those interneurons also provide input to neighboring newborn GCs.

Recording simultaneously from two cells leaves the possibility that two events will occur close in time by chance. Based on the average frequency of slow spontaneous events, the probability that two events occur by chance within a $5 \mathrm{~ms}$ time window is 1 in 625,000 [probability $(P)=P_{\text {newborn }} \times P_{\text {mature }}=(0.065 \mathrm{~Hz} \times$ $0.005 \mathrm{~s}) \times(1 \mathrm{~Hz} \times 0.005 \mathrm{~s})]$. However, we observed coincident slow events at a $40 \times$ higher rate of 1 in 15,000 [probability $(P)=$ $0.013 \mathrm{~Hz} \times 0.005 \mathrm{~s}$, where $0.013 \mathrm{~Hz}$ is the measured frequency of correlated events]. In addition, the onset measurements for coincident events were strongly correlated (supplemental Fig. 3a,b, available at www.jneurosci.org as supplemental material), with an average difference of $1.26 \pm 0.1 \mathrm{~ms}(n=105)$ (supplemental Fig. $3 c$, available at www.jneurosci.org as supplemental material). These results further suggest that correlated spontaneous events arise from a common presynaptic input to newborn and mature GCs, supporting the idea that slow PSCs in newborn GCs are analogous to $\mathrm{GABA}_{\mathrm{A} . \text { slow }}$ in mature GCs.

\section{Presynaptic regulation of GABA release at newborn and mature synapses}

In $\mathrm{CA} 1, \mathrm{GABA}_{\mathrm{A}, \mathrm{slow}}$ is under tonic suppression by endogenous activation of presynaptic $\mathrm{GABA}_{\mathrm{B}}$ receptors and $\mathrm{GABA}_{\mathrm{B}}$ receptor activation contributes to the significant depression observed during repetitive stimulation (Pearce et al., 1995; Price et al., 2005, 2008 ). In contrast, activation of presynaptic $\mathrm{GABA}_{\mathrm{B}}$ receptors by endogenous GABA has not been observed at fast GABAergic synapses (Poncer et al., 2000). We found a greater degree of pairedpulse depression of slow PSCs in newborn GCs compared with fast IPSCs in neighboring mature GCs. The PPR (300 ms interstimulus interval) in newborn GCs was $0.49 \pm 0.02(n=15)$ 
compared with $0.62 \pm 0.02$ in mature GCs $(n=14 ; p<0.001)$, and this difference was maintained across a range of different extracellular $\left[\mathrm{Ca}^{2+}\right]$ (Fig. 6a). Blocking $\mathrm{GABA}_{\mathrm{B}}$ receptors with CGP55845 $(2 \mu \mathrm{M})$ had a differential effect on both the amplitude and PPR in newborn and mature GCs. In newborn GCs, CGP55845 enhanced the amplitude of the slow PSC to $126 \pm 7 \%$ of control $(n=6 ; p<0.02)$ and increased the PPR from $0.53 \pm 0.03$ to $0.66 \pm 0.04(p<0.01)$ (Fig. $6 b)$. In contrast, CGP55845 had no effect on the amplitude (105 $\pm 6 \%$ of control; $n=5)$ or $\operatorname{PPR}(0.62 \pm 0.5$ in control vs $0.64 \pm 0.3$ in CGP) of fast IPSCs in mature GCs (Fig. $6 c$ ). The differential PPR and regulation by presynaptic $\mathrm{GABA}_{\mathrm{B}}$ receptors argues against slow PSCs arising from GABA released from the same terminals that mediate fast IPSCs. Rather, these results support the idea that slow PSCs are generated by interneurons that mediate $\mathrm{GABA}_{\mathrm{A}, \text { slow }}$.

\section{Recruitment of presynaptic}

interneurons by 4-aminopyridine

Spontaneous GABAergic synaptic events in newborn GCs are infrequent (Table 1) (Overstreet-Wadiche et al., 2005, 2006; Karten et al., 2006), and evoked PSCs are small in amplitude ( $26 \pm 2 \mathrm{pA} ; n=24)$. Even in mature GCs, $\mathrm{GABA}_{\mathrm{A} \text {,slow }}$ contributes a small fraction of spontaneous and evoked GABAergic conductance (Laplagne et al., 2006, 2007). These observations suggest that innervation of newborn GCs may be quite limited and raises the question of whether this initial synaptic signaling provides sufficient depolarization to contribute to activity-dependent regulation GC maturation. We hypothesized that synchronization of interneuron activity, as occurs during generation of various patterns of oscillatory activity in vivo (Mann and Paulsen, 2007), could activate more inputs than our focal stimulation. To test this idea, we recorded spontaneous activity in GCs in the presence of the $\mathrm{K}^{+}$ channel blocker 4-aminopyridine (4-AP). 4-AP induces robust rhythmic GABA release independent of glutamate receptor activation (Michelson and Wong, 1994), likely via propagation of activity through a network of electrically coupled interneurons (Traub et al., 2001; Zsiros et al., 2007). Bath application of 4-AP $(100 \mu \mathrm{M})$ induced large compound spontaneous GABAergic IPSCs in mature GCs (amplitude, $437 \pm 85 \mathrm{pA}$; half-width, $1.1 \pm$ $0.06 \mathrm{~s} ; n=6)$ that occurred at a low frequency ( $3.7 \pm 0.5$ events per minute) (Fig. $7 a, c$ ). The rise time of these events was slow $(158 \pm 20 \mathrm{~ms})$, often with visible inflections consistent with nearsynchronous spiking of multiple presynaptic interneurons

a newborn GC

mature GC

b

mature

C
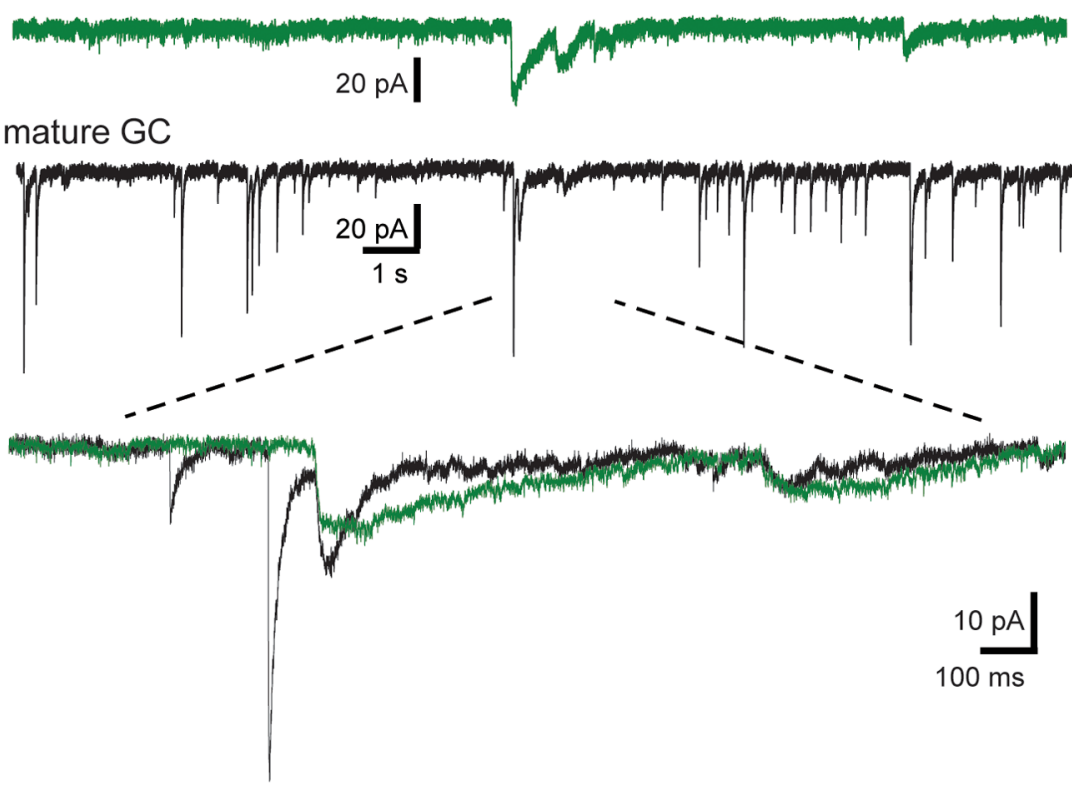
newborn GC events aligned

mature GC events aligned
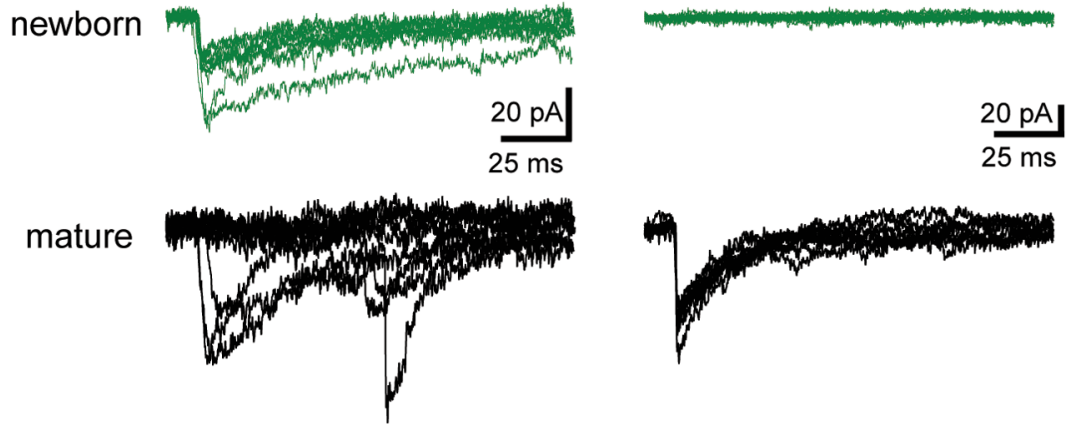

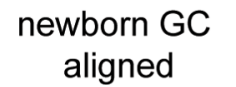

newborn

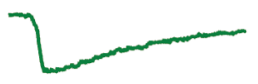

mature

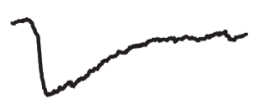

\begin{abstract}
mature GC fast aligned
\end{abstract}
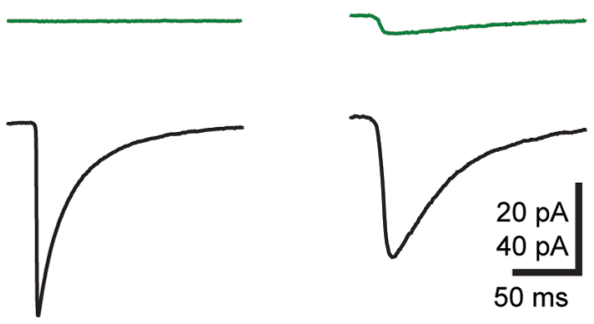

Figure 5. Coincident spontaneous currents in newborn and mature GCs. $\boldsymbol{a}$, Example traces from a simultaneously recorded newborn (green) and mature (black) GC. The inset shows the expanded region overlaid. $\boldsymbol{b}$, Left, GABAergic synaptic events in the newborn $\mathrm{GC}$ were detected and aligned, and are shown above the corresponding traces in the mature GC. Right, Fast events in the mature $\mathrm{GC}$ were detected and aligned, and are shown below the corresponding traces in the newborn GC. For clarity, 10 traces are shown for each group. $\boldsymbol{c}$, Averages of all the detected events and the corresponding traces for the cell pair shown in $\boldsymbol{b}$. Spontaneous events were aligned by the detected events in the newborn $\mathrm{GC}$ (left, average of 76 events), fast events in the mature $\mathrm{GC}$ (middle, average of 3325 events), or slow events in the mature GC (right, average of 392 events). No correlated event was evident in the newborn $\mathrm{GC}$ when fast events in the mature $\mathrm{GC}$ were averaged, whereas correlated events were present when slow events were averaged in both the newborn and mature GC. The amplitude of correlated SIPSCs in mature GCs was relatively large despite a majority of "failures" because individual correlated SIPSCs had large amplitudes. Similar results were obtained in each cell pair ( $n=$ 5) (Table 1). Calibration: 20 pA for currents in newborn GC; 40 pA for mature GC.

(Michelson and Wong, 1994). In newborn GCs, 4-AP generated events at the same frequency $(2.9 \pm 0.3$ events per minute; $n=9$; $p=0.1)$ but with a smaller amplitude $(94 \pm 24 \mathrm{pA} ; p<0.001)$ and faster time course (rise time, $45 \pm 3 \mathrm{~ms}$; half-width, $241 \pm 26$ 
Table 1. Detected and correlated spontaneous events in newborn and mature GCs

\begin{tabular}{|c|c|c|c|c|c|}
\hline & Amplitude (pA) & Rise (ms) & Decay $\tau$ (ms) & Frequency $(\mathrm{Hz})$ & \% Correlated \\
\hline \multicolumn{6}{|l|}{ Newborn GC } \\
\hline Slow & $16.6 \pm 2.8$ & $3.6 \pm 0.7$ & $88 \pm 6.0$ & $0.065 \pm 0.018$ & $21.5 \pm 4.5$ \\
\hline Slow correlated & $2.7 \pm 1.0$ & $4.2 \pm 1.2$ & $89 \pm 7.2$ & $0.013 \pm 0.003$ & - \\
\hline \multicolumn{6}{|l|}{ Mature GC } \\
\hline Fast & $62 \pm 6.7$ & $0.54 \pm 0.03^{*}$ & $27.1 \pm 1.5$ & $3.05 \pm 0.7$ & - \\
\hline Fast correlated & - & - & - & - & - \\
\hline Slow & $31.0 \pm 7.3$ & $4.0 \pm 0.2$ & $44.0 \pm 3.3^{\#}$ & $1.03 \pm 0.3$ & $1.4 \pm 0.3$ \\
\hline Slow correlated & $17.1 \pm 7.3$ & $4.0 \pm 0.5$ & $49.7 \pm 6.5^{\#}$ & $0.013 \pm 0.003$ & - \\
\hline
\end{tabular}

Spontaneous events were detected with either a fast template ( $0.5 \mathrm{~ms}$ rise time and $10 \mathrm{~ms}$ decay) or a slow template ( $5 \mathrm{~ms}$ rise and $50 \mathrm{~ms}$ decay). After detection, correlated events emerged from the averages of the aligned time windows in the simultaneously recorded cell. The amplitude, rise, and decay of correlated events were measured from the average of all traces. The frequency of correlated events was the average number of coincident events per second. The percentage correlated was calculated as the number of correlated events in the simultaneously recorded cell/total number of detected events.

*Different from slow events; ${ }^{*}$ different from fast events in mature $\mathrm{GCs}$ and slow events in newborn $\mathrm{GCs}$ ( $p<0.05$, ANOVA with Tukey-Kramer multiple comparisons).
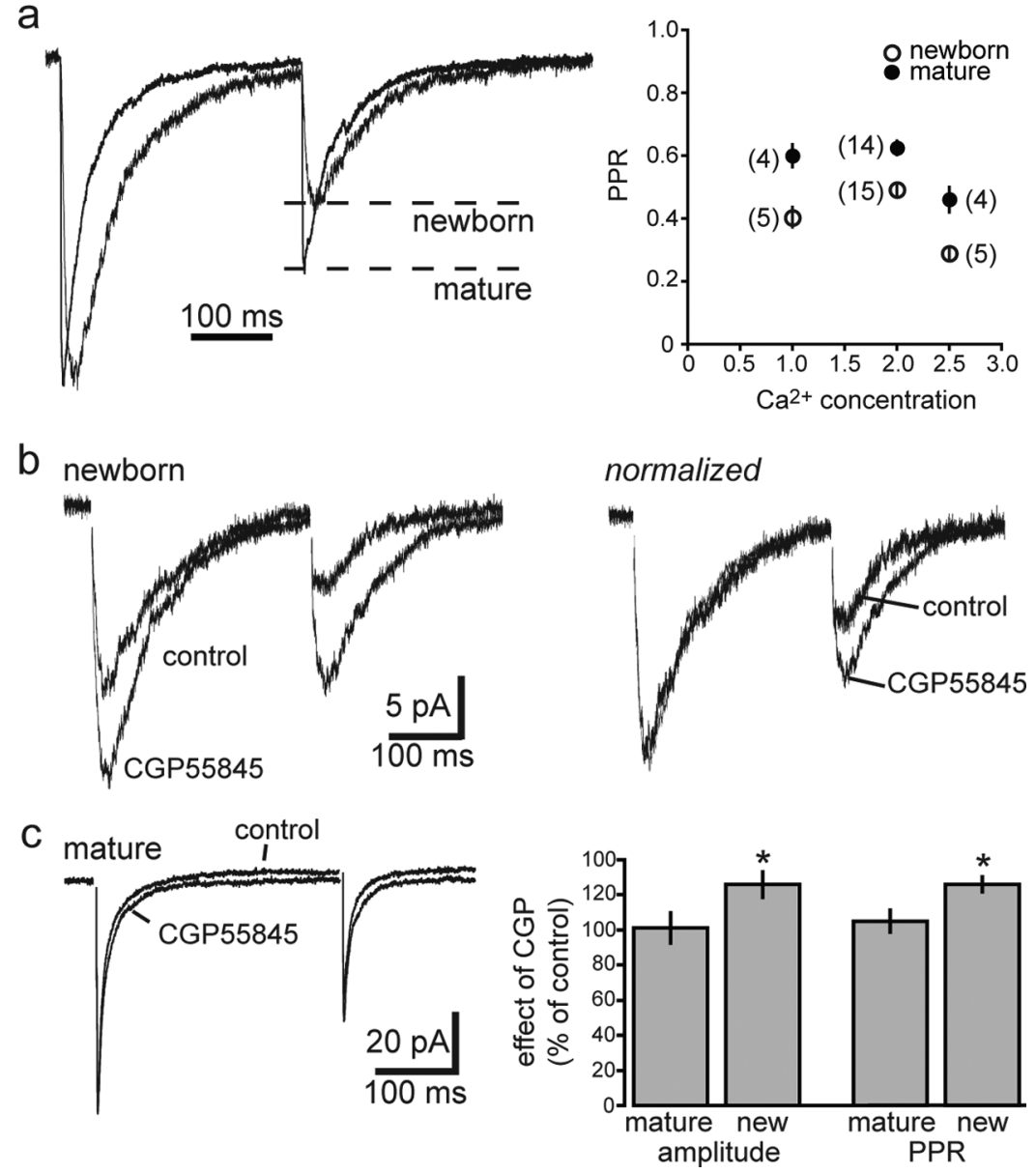

Figure 6. Presynaptic GABA $\mathrm{B}_{B}$ receptors differentially contribute to GABAergic PSCs in newborn and mature GCs. $\boldsymbol{a}$, Left, Examples of synaptic currents in newborn and mature GCs that are normalized to the peak of the first response and overlaid to illustrate the difference in the PPR. Right, At each extracellular $\mathrm{Ca}^{2+}$ concentration tested, the PPR (300 ms interstimulus interval) in newborn GCs was significantly lower than in mature GCS ( $p<0.05$, ANOVA with Student-Newman-Keuls test). The numbers in parentheses represent number of cells. $\boldsymbol{b}$, Application of the $\mathrm{GABA}_{B}$ receptor antagonist CGP55845 $(2 \mu \mathrm{M})$ increased both the amplitude (left) and paired-pulse ratio (right) of slow PSCs in newborn GCS. C, CGP55845 did not affect the amplitude or pairedpulse ratio of fast IPSCs in mature GCs. Error bars indicate SEM. ${ }^{*} p<0.05$.

ms; $p<0.001$ ) (Fig. 7b,c). The 4-AP-induced events in newborn GCs were blocked by picrotoxin (Fig. $7 b$, bottom), although rhythmic activity was still present in the network (Fig. $7 a$, bottom). These results demonstrate that 4-AP recruits lowfrequency and nearly synchronous activation of interneurons that are presynaptic to both newborn and mature GCs.

To determine how large-scale synchronous activation of presynaptic interneurons affects activity of newborn GCs, we switched to current-clamp recordings. We set the internal $\mathrm{Cl}^{-}$concentration near the predicted native $\mathrm{Cl}^{-}$concentration of newly generated GCs (23 mM) (Overstreet-Wadiche et al., 2005; Ge et al., 2006) to address whether endogenous network activity generated by 4 -AP is sufficient to drive depolarization. Indeed, 4-AP produced prolonged phasic depolarization in newborn GCs that occurred at the same low frequency as the spontaneous currents $(2.6 \pm 0.09 \mathrm{~Hz} ; n=6)$ (Fig. $8 a, b)$. The peak amplitude of synaptic GABAergic depolarization was $35 \pm 3 \mathrm{mV}(69$ events from six cells), bringing the membrane potential to $-39 \pm 2 \mathrm{mV}$ from a resting potential held at $-74 \pm 1 \mathrm{mV}$. Notably, GABAergic depolarizations were long lasting (half-width of $1.7 \pm 0.09 \mathrm{~s}$ ), reflecting the slow underlying synaptic conductance and membrane time constant of newborn GCs, and possible activation of voltage-gated conductances (Overstreet et al., 2004; Schmidt-Hieber et al., 2004). These results demonstrate that hippocampal network activity can generate robust depolarization of newborn GCs via slow GABAergic synaptic signaling.

\section{Discussion}

Our results show that the spatiotemporal properties of the GABA transient underlying slow PSCs in newborn GCs differ from those underlying fast IPSCs in mature GCs and further suggest that the characteristics of the GABA transient contribute to the slow timing of PSCs in newborn GCs. Although slow PSCs have some properties of GABA spillover from nearby synapses, such as high sensitivity to blockade of GABA transporters and to a low-affinity competitive antagonist, our results are inconsistent with the conclusion that PSCs are mediated by nonspecific spillover from mature perisomatic synapses. For instance, the differential paired-pulse ratio and regulation by presynaptic $\mathrm{GABA}_{\mathrm{B}}$ receptors, as well as the response to low extracellular $\left[\mathrm{Ca}^{2+}\right]$ support the alternative idea that slow PSCs are generated by specific inputs that exhibit a 
mode of synaptic transmission intermediate between phasic and tonic GABA signaling that has recently been described in the cortex (Szabadics et al., 2007).

Together with previous studies, our results indicate that multiple mechanisms converge to enable robust depolarization of newborn GCs by GABA. At the synaptic level, the unusual GABA transient and the identity of postsynaptic $\mathrm{GABA}_{\mathrm{A}}$ receptors that lack the rapid-gating $\alpha 1$ subunit (Overstreet-Wadiche et al., 2005; Karten et al., 2006) act in concert to produce a prolonged $\mathrm{GABA}_{\mathrm{A}}$ receptor-mediated synaptic conductance. At the cellular level, the high intracellular $\left[\mathrm{Cl}^{-}\right]$of newborn cells means that GABA-evoked currents are depolarizing (Overstreet-Wadiche et al., 2005; Tozuka et al., 2005; Ge et al., 2006). In addition, the high membrane resistance and slow membrane time constant of newborn GCs (Overstreet et al., 2004; Schmidt-Hieber et al., 2004) promote membrane depolarization in response to modest synaptic input. At the network level, synapses arising from interneurons coupled by gap junctions allow robust synaptic activation of newborn GCs when the interneuron network is engaged, as we observed in 4-AP. Although it is not clear whether 4-AP-induced network activity in acute slices has physiological or pathological correlates in vivo, our results show that newborn GCs are primed at multiple levels to convert hippocampal interneuron activity into robust membrane depolarization.

\section{The GABA concentration profile at newborn synapses}

Manipulating the GABA transient by impairing GABA uptake and diffusion revealed differences between the spatiotemporal profile of transmitter underlying slow and fast synaptic responses. At fast perisomatic synapses, neuronal GABA uptake has minimal effects on the peak amplitude and time course of transmitter within the cleft but acts to limit the spread of GABA between adjacent synapses when many synapses are simultaneously activated (Isaacson et al., 1993; Overstreet et al., 2002; Overstreet and Westbrook, 2003). However, both GABA transporters and diffusion strongly limited the amplitude PSCs in newborn GCs. Along with the effect of the low-affinity antagonist, these results suggest that the peak GABA concentration is lower at newborn synapses than at fast synapses on mature GCs. The dramatic prolongation of both the rise and decay of the slow PSC by NO711 also suggests that the spatial spread of transmitter at newborn synapses differs from typical fast synapses. Indeed, the only manipulation that sped the decay of slow PSCs was to impair diffusion with dextran. Reducing the diffusion of transmitter with dextran has been used to distinguish the relative distance of activated receptors from the transmitter release site, because responses generated by distant receptors (by spillover) are slowed with no change in amplitude, whereas responses mediated by receptors close to the release site could are enhanced with no change in rise time (Nielsen et al., 2004). Thus, the enhanced PSC amplitude in dextran with no change in rise time suggests receptors close to the release site could contribute to the slow PSC in newborn GCs. Following similar reasoning, the speeding of the

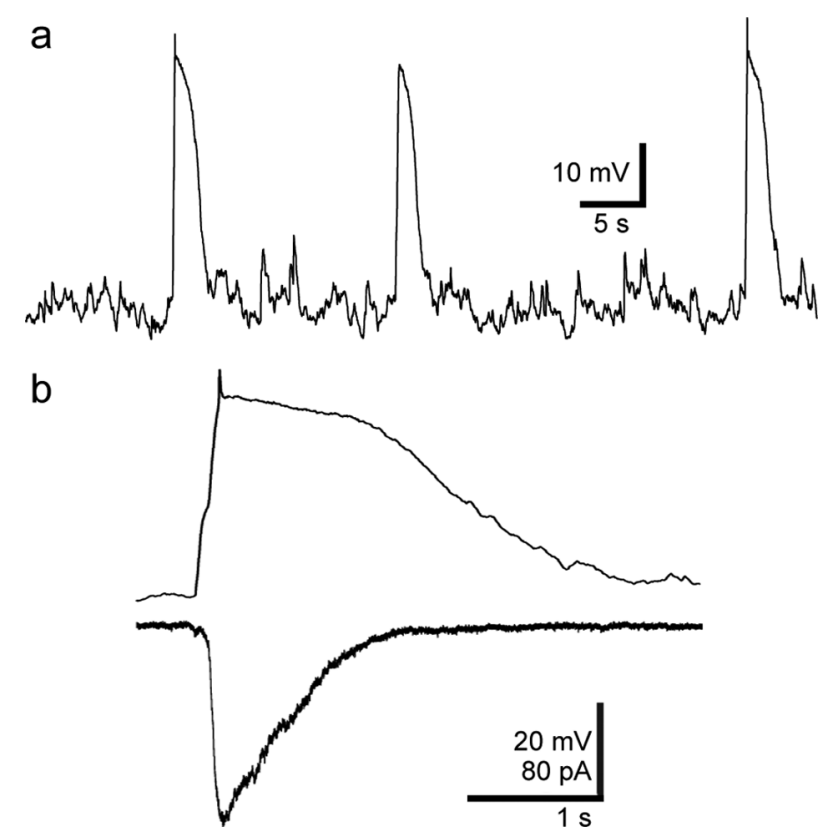

Figure 8. 4-AP-induced network activity generates robust depolarization of newborn GCs. $\boldsymbol{a}$, Representative example of a current-clamp recording from a newborn GC in 4-AP. Spontaneous phasic depolarizations were observed in all cells $(n=6) . \boldsymbol{b}$, Comparison of 4-AP-induced events in the same newborn $\mathrm{GC}$ in current-clamp (top) and voltage-clamp recording mode (bottom).

PSC decay may result from a reduction in GABA diffusion to distant receptors. This situation could result from receptors that are distributed across the synaptic and perisynaptic region rather than clustered below the release site. However, a potential caveat to these results is that it is not known whether all synapses are equally accessible to dextran. 
Our data suggesting that the GABA transient promotes slow PSCs in newborn GCs do not rule out a contribution by the subunit composition of the postsynaptic receptors. Rather, the kinetics of postsynaptic receptor gating are implicated by the observation that newborn GCs lack expression of the fast gating $\alpha 1 \mathrm{GABA}_{\mathrm{A}}$ receptor subunit (Overstreet-Wadiche et al., 2005; Karten et al., 2006) and that spontaneous slow PSCs have a slower decay time than slow IPSCs in mature GCs (Table 1). Different subunit composition potentially confounds the interpretation of the differential block by TPMPA, because an implicit assumption in the ability of a low-affinity antagonist to differentiate between transmitter concentrations is that the underlying receptors have a similar affinity for the antagonist. This is an unlikely confound, however, because competitive antagonists over a large range of affinities act independently of receptor subunit composition (Ebert et al., 1997; Rahman et al., 2006) and the high-affinity antagonist SR95531 (gabazine) was equally efficacious at blocking fast and slow responses. Furthermore, the enhancement of slow PSCs by dextran indicates the postsynaptic receptors are far from saturation, thereby independently corroborating the lower relative GABA transient compared with IPSCs in mature GCs that are not enhanced in dextran. Future studies with subunitspecific $\mathrm{GABA}_{\mathrm{A}}$ receptor modulators will focus on subunits that contribute to $\mathrm{GABA}_{\mathrm{A} \text {,slow }}$ in CA1 pyramidal cells that are also far from saturation after synaptic activation (Zarnowska et al., 2009).

\section{GABA spillover versus dedicated inputs}

Several of our findings support the idea that slow PSCs in newborn GCs are not produced by spillover from neighboring perisomatic synapses on mature GCs. First, newborn GCs exhibit miniature PSCs (Karten et al., 2006) and morphologically identified synapses (Ide et al., 2008), making it likely, although not certain, that evoked PSCs are generated at those sites. Second, reducing the number of GABA release sites by lowering extracellular $\left[\mathrm{Ca}^{2+}\right]$ decreased the slow PSC amplitude to the same extent as the fast IPSC amplitude, inconsistent with a nonlinear effect of GABA pooling (Scanziani, 2000). Third, spontaneous slow PSCs in newborn GCs were coincident with slow, but not fast, IPSCs in mature GCs. Fourth, PSCs in newborn GCs display a different PPR than fast IPSCs in mature GCs as well as differential modulation by presynaptic $\mathrm{GABA}_{\mathrm{B}}$ receptors. Although postsynaptic receptor properties such as enhanced desensitization could in theory contribute to different PPRs, it is unlikely that desensitization underlies the differential effect of $G_{A B A}$ receptor blockade on the initial amplitude and PPR. Finally, a comparison of the 4-AP-induced spontaneous activity in newborn and mature GCs is inconsistent with GABA spillover. If the 4-AP-induced currents in newborn GCs resulted from spillover from the same events in mature GCs, we expect the responses in newborn GCs to be slower to rise and longer lasting compared with the events in mature GCs. However, both the rise time and half-width of the 4-AP-induced events were faster in newborn GCs.

\section{The source of GABAergic input to newborn GCs}

Dendritic projecting interneurons provide the first source of input to newborn GCs, with subsequent addition of fast perisomatic synapses only after several weeks of maturation (Espósito et al., 2005). Here, we show that slow PSCs in newborn GCs respond to NO711, dextran, and TPMPA in a manner that strongly resembles $\mathrm{GABA}_{\mathrm{A} \text {,slow }}$ evoked by single neurogliaform cells (Szabadics et al., 2007). Neurogliaform interneurons have dendritic- projecting axonal arbors with numerous small synaptic boutons that generate slow $\mathrm{GABA}_{\mathrm{A}}$ receptor-meditated inhibition in principal and nonprincipal neurons (Oláh et al., 2007). It is not clear how the unusual GABA transient is generated, but structural features such as a small synaptic cleft diameter in combination with a large cleft height (Szabadics et al., 2007) or the lack of a one-toone relationship between presynaptic and postsynaptic elements could contribute to a restricted form of volume transmission (Oláh et al., 2009). Our results are consistent with the possibility that neurogliaform interneurons, or the related Ivy cell (Fuentealba et al., 2008), provide the initial source of GABAergic signaling to adult generated GCs. Our results further suggest that stimulation in perisomatic regions is capable of activating such "dendritic" projecting inputs that may contribute to the spillover-like characteristics of late components of fast-evoked IPSCs in mature GCs (Overstreet and Westbrook, 2003).

Discriminating spillover-mediated transmission from neighboring fast synapses from a spillover-like mode of transmission arising from dedicated inputs has consequences for understanding activity-dependent regulation of newborn GC maturation. The former case is expected to generate depolarization of newborn GCs as a nonspecific response to hippocampal network activity, similar to tonic GABAergic signaling (Ge et al., 2008). However, the latter case provides input-specific depolarization that could potentially contribute to experience-dependent wiring of the hippocampal circuit, as suggested for NMDA receptor activation (Tashiro et al., 2006). Although the intracellular signaling pathways triggered by GABAergic depolarization are not yet known, slow GABAergic signaling to newborn GCs may represent a key step in activity-dependent regulation of neurogenesis.

\section{References}

Biró AA, Nusser Z (2005) Synapse independence breaks down during highly synchronous network activity in the rat hippocampus. Eur J Neurosci 22:1257-1262.

Clements JD (1996) Transmitter timecourse in the synaptic cleft: its role in central synaptic function. Trends Neurosci 19:163-171.

Cobb SR, Buhl EH, Halasy K, Paulsen O, Somogyi P (1995) Synchronization of neuronal activity in hippocampus by individual GABAergic interneurons. Nature 378:75-78.

Cowley MA, Smart JL, Rubinstein M, Cerdán MG, Diano S, Horvath TL, Cone RD, Low MJ (2001) Leptin activates anorexigenic POMC neurons through a neural network in the arcuate nucleus. Nature 411:480-484.

Deisseroth K, Singla S, Toda H, Monje M, Palmer TD, Malenka RC (2004) Excitation-neurogenesis coupling in adult neural stem/progenitor cells. Neuron 42:535-552.

Diamond JS (2001) Neuronal glutamate transporters limit activation of NMDA receptors by neurotransmitter spillover on CA1 pyramidal cells. J Neurosci 21:8328-8338.

Ebert B, Thompson SA, Saounatsou K, McKernan R, Krogsgaard-Larsen P, Wafford KA (1997) Differences in agonist/antagonist binding affinity and receptor transduction using recombinant human gamma-aminobutyric acid type A receptors. Mol Pharmacol 52:1150-1156.

Espósito MS, Piatti VC, Laplagne DA, Morgenstern NA, Ferrari CC, Pitossi FJ, Schinder AF (2005) Neuronal differentiation in the adult hippocampus recapitulates embryonic development. J Neurosci 25:10074-10086.

Farrant M, Nusser Z (2005) Variations on an inhibitory theme: phasic and tonic activation of $\mathrm{GABA}_{\mathrm{A}}$ receptors. Nat Rev Neurosci 6:215-229.

Fuentealba P, Begum R, Capogna M, Jinno S, Márton LF, Csicsvari J, Thomson A, Somogyi P, Klausberger T (2008) Ivy cells: a population of nitric-oxideproducing, slow-spiking GABAergic neurons and their involvement in hippocampal network activity. Neuron 57:917-929.

Ge S, Goh EL, Sailor KA, Kitabatake Y, Ming GL, Song H (2006) GABA regulates synaptic integration of newly generated neurons in the adult brain. Nature 439:589-593.

Ge S, Sailor KA, Ming GL, Song H (2008) Synaptic integration and plasticity of new neurons in the adult hippocampus. J Physiol 586:3759-3765.

Häusser M, Roth A (1997) Estimating the time course of the excitatory syn- 
aptic conductance in neocortical pyramidal cells using a novel voltage jump method. J Neurosci 17:7606-7625.

Ide Y, Fujiyama F, Okamoto-Furuta K, Tamamaki N, Kaneko T, Hisatsune T (2008) Rapid integration of young newborn dentate gyrus granule cells in the adult hippocampal circuitry. Eur J Neurosci 28:2381-2392.

Isaacson JS, Solís JM, Nicoll RA (1993) Local and diffuse synaptic actions of GABA in the hippocampus. Neuron 10:165-175.

Karten YJ, Jones MA, Jeurling SI, Cameron HA (2006) GABAergic signaling in young granule cells in the adult rat and mouse dentate gyrus. Hippocampus 16:312-320.

Laplagne DA, Espósito MS, Piatti VC, Morgenstern NA, Zhao C, van Praag H, Gage FH, Schinder AF (2006) Functional convergence of neurons generated in the developing and adult hippocampus. PLoS Biol 4:e409.

Laplagne DA, Kamienkowski JE, Espósito MS, Piatti VC, Zhao C, Gage FH, Schinder AF (2007) Similar GABAergic inputs in dentate granule cells born during embryonic and adult neurogenesis. Eur J Neurosci 25:29732981.

Mann EO, Paulsen O (2007) Role of GABAergic inhibition in hippocampal network oscillations. Trends Neurosci 30:343-349.

Markwardt S, Overstreet-Wadiche L (2008) GABAergic signalling to adultgenerated neurons. J Physiol 586:3745-3749.

Matsui K, Jahr CE (2003) Ectopic release of synaptic vesicles. Neuron 18:1173-1183.

Michelson HB, Wong RK (1994) Synchronization of inhibitory neurones in the guinea-pig hippocampus in vitro. J Physiol 477:35-45.

Miles R, Tóth K, Gulyás AI, Hájos N, Freund TF (1996) Differences between somatic and dendritic inhibition in the hippocampus. Neuron 16:815823.

Min MY, Rusakov DA, Kullmann DM (1998) Activation of AMPA, kainate, and metabotropic receptors at hippocampal mossy fiber synapses: role of glutamate diffusion. Neuron 21:561-570.

Mozrzymas JW (2004) Dynamism of $\mathrm{GABA}_{\mathrm{A}}$ receptor activation shapes the "personality" of inhibitory synapses. Neuropharmacology 47:945-960.

Nielsen TA, DiGregorio DA, Silver RA (2004) Modulation of glutamate mobility reveals the mechanism underlying slow-rising AMPAR EPSCs and the diffusion coefficient in the synaptic cleft. Neuron 42:757-771.

Oláh S, Komlósi G, Szabadics J, Varga C, Tóth E, Barzó P, Tamás G (2007) Output of neurogliaform cells to various neuron types in the human and rat cerebral cortex. Front Neural Circuits 1:4.

Oláh S, Füle M, Komlósi G, Varga C, Báldi R, Barzó P, Tamás G (2009) Regulation of cortical microcircuits by unitary GABA-mediated volume transmission. Nature 461:1278-1281.

Overstreet LS, Westbrook GL (2001) Paradoxical reduction of synaptic inhibition by vigabatrin. J Neurophysiol 86:596-603.

Overstreet LS, Westbrook GL (2003) Synapse density regulates independence at unitary inhibitory synapses. J Neurosci 23:2618-2626.

Overstreet LS, Westbrook GL, Jones MV (2002) Measuring and modeling the spatiotemporal profile of GABA at the synapse. In: Transmembrane transporters (Quick M, ed), pp 259-275. New York: Wiley.

Overstreet LS, Hentges ST, Bumaschny VF, de Souza FS, Smart JL, Santangelo AM, Low MJ, Westbrook GL, Rubinstein M (2004) A transgenic marker for newly born granule cells in dentate gyrus. J Neurosci 24:3251-3259.

Overstreet-Wadiche L, Bromberg DA, Bensen AL, Westbrook GL (2005) GABAergic signaling to newborn neurons in dentate gyrus. J Neurophysiol 94:4528-4532.

Overstreet-Wadiche LS, Bensen AL, Westbrook GL (2006) Delayed devel- opment of adult-generated granule cells in dentate gyrus. J Neurosci 26:2326-2334.

Pearce RA (1993) Physiological evidence for two distinct GABAA responses in rat hippocampus. Neuron 10:189-200.

Pearce RA, Grunder SD, Faucher LD (1995) Different mechanisms for usedependent depression of two GABAA-mediated IPSCs in rat hippocampus. J Physiol 484:425-435.

Perrais D, Ropert N (2000) Altering the concentration of GABA in the synaptic cleft potentiates miniature IPSCs in rat occipital cortex. Eur J Neurosci 12:400-404.

Poncer JC, McKinney RA, Gahwiler BH, Thompson SM (2000) Differential control of GABA release at synapses from distinct interneurons in rat hippocampus. J Physiol 528:123-130.

Pouille F, Scanziani M (2001) Enforcement of temporal fidelity in pyramidal cells by somatic feed-forward inhibition. Science 293:1159-1163.

Price CJ, Cauli B, Kovacs ER, Kulik A, Lambolez B, Shigemoto R, Capogna M (2005) Neurogliaform neurons form a novel inhibitory network in the hippocampal CA1 area. J Neurosci 25:6775-6786.

Price CJ, Scott R, Rusakov DA, Capogna M (2008) GABA $_{B}$ receptor modulation of feedforward inhibition through hippocampal neurogliaform cells. J Neurosci 28:6974-6982.

Rahman M, Zhu D, Lindblad C, Johansson IM, Holmberg E, Isaksson M, Taube M, Backstrom T, Wang MD (2006) GABA-site antagonism and pentobarbital actions do not depend on the alpha-subunit type in the recombinant rat GABA receptor. Acta Physiol (Oxf) 187:479-488.

Rossi DJ, Hamann M (1998) Spillover-mediated transmission at inhibitory synapses promoted by high affinity alpha6 subunit $\mathrm{GABA}_{\mathrm{A}}$ receptors and glomerular geometry. Neuron 20:783-795.

Scanziani M (2000) GABA spillover activates postsynaptic $\mathrm{GABA}_{\mathrm{B}}$ receptors to control rhythmic hippocampal activity. Neuron 25:673-681.

Schmidt-Hieber C, Jonas P, Bischofberger J (2004) Enhanced synaptic plasticity in newly generated granule cells of the adult hippocampus. Nature 429:184-187.

Soltesz I, Smetters DK, Mody I (1995) Tonic inhibition originates from synapses close to the soma. Neuron 14:1273-1283.

Szabadics J, Tamás G, Soltesz I (2007) Different transmitter transients underlie presynaptic cell type specificity of GABAA,slow and GABAA,fast. Proc Natl Acad Sci U S A 104:14831-14836.

Tamás G, Lorincz A, Simon A, Szabadics J (2003) Identified sources and targets of slow inhibition in the neocortex. Science 299:1902-1905.

Tashiro A, Sandler VM, Toni N, Zhao C, Gage FH (2006) NMDA-receptormediated, cell-specific integration of new neurons in adult dentate gyrus. Nature 442:929-933.

Tozuka Y, Fukuda S, Namba T, Seki T, Hisatsune T (2005) GABAergic excitation promotes neuronal differentiation in adult hippocampal progenitor cells. Neuron 47:803-815.

Traub RD, Bibbig R, Piechotta A, Draguhn R, Schmitz D (2001) Synaptic and nonsynaptic contributions to giant IPSPs and ectopic spikes induced by 4 -aminopyridine in the hippocampus in vitro. J Neurophysiol 85:1246-1256.

Zarnowska ED, Keist R, Rudolph U, Pearce RA (2009) GABAA receptor $\alpha 5$ subunits contribute to GABAA,slow synaptic inhibition in mouse hippocampus. J Neurophysiol 101:1179-1191.

Zsiros V, Aradi I, Maccaferri G (2007) Propagation of postsynaptic currents and potentials via gap junctions in GABAergic networks of the rat hippocampus. J Physiol 578:527-544. 